\title{
Comparison of the utilization of endoscopy units in selected teaching hospitals across Canada
}

\author{
E LALOR MB ChB FRCPC FRACP, ABR THOMSON MD PhD FRCPC FACG
}

\begin{abstract}
E LALOR, ABR THOMSON. Comparison of the utilization of endoscopy units in selected teaching hospitals across Canada. Can J Gastroenterol 1996;10(6):381-384. There is no information on the number of endoscopic procedures performed at major teaching hospitals across Canada. The directors of endoscopy units at eight teaching hospitals from Halifax to Vancouver volunteered demographic information on the unit at their location. There was a very wide range of endoscopic utilization, with approximately comparable rates of out-patient versus in-patient procedures and of gastroscopies versus colonoscopies, but there was no obvious linking of the ratios of in-patients:out-patients versus total number of designated gastrointestinal beds or total number of hospital beds. Thus, the appropriateness of endoscopic procedures needs to be based on standards of practice and accepted indications. The number of endoscopies performed per endoscopy unit support staff varied widely (from 323.7 to 1065.3 per year), and it would be interesting to learn whether this represents an opportunity for cost-saving in some units.
\end{abstract}

Key Words: Cost savings, Endoscopy, Teaching hospital

\section{Utilisation comparative de l'endoscopie dans les hôpitaux universitaires au Canada}

RÉSUMÉ : On ignore le nombre d'interventions endoscopiques effectuées dans les grands hôpitaux universitaires du Canada. Les directeurs des unités d'endoscopie de huit hôpitaux d'enseignement universitaire, de Halifax à Vancouver, se sont portés volontaires pour recueillir des données démographiques sur l'endoscopie dans leur établissement. On note une grande variation quant à l'utilisation de l'endoscopie, les proportions de patients ambulatoires versus patients hospitalisés étant à peu près comparables, de même que les taux de gastroscopies versus coloscopies. Mais on n'a pu déceler aucun lien entre les ratios de patients hospitalisés:ambulatoires et le nombre total de lits réservés à la gastro-entérologie ou le nombre total de lits de l'hôpital. Ainsi, le bien-fondé des interventions d'endoscopie doit se baser sur les normes et les indications appropriées. Le nombre d'endoscopies effectuées en proportion du personnel de soutien de l'unité variait grandement (de 323,7 à 1 065,3 par année). Il serait intéressant de découvrir si cela peut générer des économies dans certaines unités.
A 11 medical services in Canada, including gastroenterological endoscopy, are coming under increasing scrutiny. The importance and role of diagnostic and therapeutic endoscopy has been firmly established. Guidelines for the assessment of indications and outcome have been reported and are in place in a number of endoscopic units across Canada. The potential usefulness of endoscopy is often challenged, particularly when discussing physician's fees and resource utilization. There is a paucity of information avail- able on the number of endoscopic procedures performed at major teaching hospitals across this country, the distribution of procedures, the proportion of in-patient versus out-patient procedures and the staffing of the endoscopic units. Accordingly, the directors of endoscopy units at eight teaching hospitals from Halifax to Vancouver were asked to provide demographic information on the unit at their location. This information was freely provided and is the basis of this report. 
TABLE 1

Number of gastroscopies, colonoscopies and endoscopic retrograde cholangiopancreatographies (ERCPs) in eight Canadian teaching hospitals

\begin{tabular}{lcccc}
\hline Hospital \# & Gastroscopies & Colonoscopies & ERCPs & Total \\
\hline 1 & $3831(68.5 \%)$ & $1430(25.6 \%)$ & $332(5.9)$ & 5593 \\
2 & $2051(57.5 \%)$ & $1409(39.5 \%)$ & $106(3.0)$ & 3566 \\
3 & $3980(62.3 \%)$ & $1895(29.7 \%)$ & $514(8.0)$ & 6392 \\
4 & $2928(60.2 \%)$ & $1634(33.6 \%)$ & $299(6.2)$ & 4861 \\
5 & $1205(50.9 \%)$ & $640(32.6 \%)$ & $121(6.2)$ & 1966 \\
6 & $3210(61.9 \%)$ & $1769(34.1 \%)$ & $210(4.0)$ & 5189 \\
$7^{*}$ & - & - & - & 5996 \\
8 & $1417(62.5 \%)$ & $707(31.2 \%)$ & $142(6.3)$ & 2266 \\
\hline
\end{tabular}

${ }^{*}$ Data on individual procedures not recorded

TABLE 2

Distribution of all endoscopic procedures including sigmoidoscopies

\begin{tabular}{lccc}
\hline $\begin{array}{l}\text { Hospital } \\
\#\end{array}$ & $\begin{array}{c}\text { Annual total } \\
\text { number }\end{array}$ & $\begin{array}{c}\text { In-patient total } \\
\text { number (\%) }\end{array}$ & $\begin{array}{c}\text { Out-patient total } \\
\text { number (\%) }\end{array}$ \\
\hline 1 & 7737 & $1971(25.5)$ & $5766(74.5)$ \\
2 & 4600 & $1150(25.0)$ & $3450(75.0)$ \\
3 & 6507 & $911(14.0)$ & $5596(86.0)$ \\
4 & 5914 & $1731(29.3)$ & $4184(50.8)$ \\
5 & 2690 & $1056(39.3)$ & $1634(60.7)$ \\
6 & 6511 & $-(0)$ & $-(0)$ \\
7 & 5996 & $1536(25.6)$ & $4460(74.4)$ \\
8 & 4042 & $852(21.1)$ & $3190(78.9)$ \\
Mean & 5499.6 & $(25.67)$ & $(74.3)$ \\
SD & 1616.4 & $(11.5)$ & $(27.23)$ \\
\hline
\end{tabular}

TABLE 3

Total number of gastroscopy, colonoscopy and endoscopic retrograde cholangiopancreatography procedures

\begin{tabular}{lcccc}
\hline \multicolumn{2}{l}{$\begin{array}{c}\text { Hosp Procedures// } \\
\text { \# }\end{array}$} & $\begin{array}{c}\text { Procedures/ } \\
\text { endoscopist/ } \\
\text { year }\end{array}$ & $\begin{array}{c}\text { Procedures/ } \\
\text { in-patient } \\
\text { bed/year }\end{array}$ & $\begin{array}{c}\text { Procedures/ } \\
\text { designated } \\
\text { Gl bed/year }\end{array}$ \\
\hline 1 & 5593 & 466.1 & 7.0 & 310.7 \\
2 & 3566 & 254.7 & 5.6 & 594.3 \\
3 & 6392 & 799.0 & 9.8 & 1278.4 \\
4 & 4861 & 607.6 & 8.4 & 607.6 \\
5 & 1966 & 655.3 & 9.1 & 109.2 \\
6 & 5189 & 259.5 & - & 305.2 \\
7 & 5996 & 599.6 & 7.9 & - \\
8 & 2266 & 251.8 & 6.0 & - \\
Mean & 4478.6 & 358.9 & 7.7 & 534.2 \\
\hline
\end{tabular}

Gl Gastrointestinal; Hosp Hospital

\section{MATERIALS AND METHODS}

A questionnaire was circulated to the director of gastrointestinal endoscopy at eight major teaching hospitals in Canada: Victoria General Hospital/Camp Hill Medical Centre, Halifax, Nova Scotia; Montreal General Hospital, Montreal, Quebec; Hotel Dieu Hospital, Kingston, Ontario; McMaster/Chedoke Hospital, Hamilton, Ontario; St Michael's Hospital, Toronto, Ontario; Royal Alexandra Hospital, Edmonton, Alberta; Walter Mackenzie Health Sciences
Centre, Edmonton, Alberta; and St Paul's Hospital, Vancouver, British Columbia. For purposes of confidentiality, the data for each institution are presented using a code designation.

\section{RESULTS}

The total number of gastroscopies, colonoscopies and endoscopic retrograde cholangiopancreatographies (ERCPs) performed at each of the eight units in 1992 varied from 1966 to 6392 (Table 1). In one unit only the total number of procedures was recorded. Gastroscopies represented the majority of the procedures, with $50.9 \%$ to $68.5 \%$; colonoscopies represented $25.5 \%$ to $39.5 \%$ and ERCPs represented $3.0 \%$ to $6.3 \%$. The absolute number of ERCPs performed each year varied widely, from 106 to 332 . The survey did not distinguish between diagnostic and therapeutic ERCPs. A total of $60.7 \%$ to $86.0 \%$ of these three procedures were performed on out-patients and $14.0 \%$ to $39.3 \%$ were performed on inpatients (Table 2).

A ratio of procedures per descriptor unit was derived. Because the total patient base was unknown, these endoscopic numbers (gastroscopies, colonoscopies and ERCPs) were expressed on the basis of total endoscopic procedures per in-patient bed or per endoscopist. The number of inpatient beds per hospital ranged from 217 to 804 . The number of endoscopies per year per total number of in-patient beds ranged from 6.0 to 9.8 (Table 3). Two hospitals did not have designated gastrointestinal in-patient beds, while the remaining units had from five to 18 gastrointestinal beds. The number of endoscopic procedures performed per year per gastrointestinal bed varied from 109.2 to 1278.4 .

The workload on the support staff, including receptionists and endoscope cleaners, in the endoscopy units was determined. The number of registered nurses (RNs) per unit varied from two to eight, and the number of other support staff varied from 1.5 to six (Table 4). Total number of endoscopies per RN varied from 453 to 1398, and the number of total endoscopies per total support staff including $\mathrm{RNs}$ varied from 323.7 to 1065.3 .

\section{DISCUSSION}

There was a 10 -fold difference in the number of endoscopic procedures performed on the basis of a designated gastrointestinal bed, and a 150\% difference between centres in the number of endoscopies per in-patient bed. The workload per RN in the endoscopy unit varied by a factor of five and the workload for total number of support staff varied threefold. Thus, there was no consistent trend in these eight major teaching hospitals that allowed prediction of the number of appropriate procedures per descriptive designator. Furthermore, there does not appear to be any consistent level of support staff in these units.

Gastroscopies clearly represent the greater proportion of endoscopic procedures (between $50.9 \%$ and $68.5 \%$ of all endoscopic procedures were gastroscopies). From institution to institution the numbers varied from 1205 to 3980 per year. The total number of colonoscopies varied between 640 and 


\section{TABLE 4}

Number of staff in the endoscopy units

\begin{tabular}{|c|c|c|c|c|c|c|}
\hline $\begin{array}{l}\text { Hospital } \\
\#\end{array}$ & $\begin{array}{c}\text { Number of } \\
\text { endoscopists }\end{array}$ & $\begin{array}{c}\text { Number of } \\
\text { registered nurses }\end{array}$ & $\begin{array}{l}\text { Number of } \\
\text { other staff }\end{array}$ & $\begin{array}{l}\text { Total number of } \\
\text { endoscopy staff }\end{array}$ & $\begin{array}{l}\text { Total procedures/ } \\
\text { registered nurse/year }\end{array}$ & $\begin{array}{l}\text { Total procedures/ } \\
\text { endoscopy staff/year }\end{array}$ \\
\hline 2 & 14 & 5.2 & 1.5 & 6.7 & 685.8 & 532.2 \\
\hline 4 & 8 & 4 & 4 & 8 & 1215.3 & 607.6 \\
\hline 5 & 3 & 2 & 1.5 & 3.5 & 983 & 561.7 \\
\hline 6 & 20 & 8 & 6 & 14 & 648.6 & 370.6 \\
\hline 8 & 9 & 5 & 2 & 7 & 453.2 & 323.7 \\
\hline
\end{tabular}

1898 per year (Table 1), and there was no obvious relationship between the number or proportions of gastroscopies and colonoscopies. This variability likely represents local referral patterns and physician interest.

The number of ERCPs performed per year depends on the interest of the teaching unit, the skill of attending physicians and the demands placed by affiliated laparoscopic and transplantation programs. In this study, the number of annual procedures ranged from 106 to 514. Minimum standards have been set for the number of ERCPs required before a gastroenterology training fellow may achieved a minimal standard of competence. Indeed, there is controversy whether diagnostic ERCPs should be taught to all gastrointestinal trainees. The results of this survey clearly raise concern because some centres may not perform sufficient ERCPs to provide a minimum basis for this important diagnostic and therapeutic skill.

With the steady reduction in the number of available in-patient beds, more gastrointestinal endoscopy procedures are being performed on out-patients. In each of the eight centres surveyed, at least two-thirds of total endoscopic procedures were performed on out-patients (Table 2). No relationship existed between the number of designated gastrointestinal in-patient beds and the percentage of out-patient endoscopies, and there was no relationship found between the number of total in-patients beds and the proportion of out-patient endoscopies.

The job description of gastroenterologists in teaching hospitals varies from a major emphasis on clinical practice and teaching to a major emphasis on research. Only the total number of endoscopists performing procedures is available, with no information on the proportion of their time used to care for patients or to perform endoscopies. In this study, it was not specified whether the endoscopist was a physician, surgeon, radiologist or pediatrician. Thus, the wide variation in the total number of endoscopies performed each year per endoscopist (Table 3) likely represents physician interest and job descriptions, rather than any difference in endoscopy indications or utilization.

Every endoscopy unit across Canada is under pressure because of economic downsizing and every effort must be made to identify possibilities for cost containment. The number of endoscopies performed in each unit per year per
$\mathrm{RN}$, or more importantly per total number of support staff, varied widely. Some units have proportionately more nurses, whereas other units may depend heavily on nursing assistants. In this survey, the nature of support staff other than RNs was not defined, and these persons may have been endoscopic assistants, receptionists or endoscope cleaners. In some units endoscopies may be performed without an $\mathrm{RN}$ in attendance and some units may make proportionately more use of endoscope washing machines versus cleaning by support staff. Nonetheless, the total number of endoscopies performed per support staff varied immensely - from 370.6 to 1065.3 per year (Table 4). This may represent an opportunity for some units to save on their annual budget allocations for support staff. It would be useful and interesting to learn how the high volume per personnel unit (such as hospital numbers 1, 3 and 7) were able to achieve this workload and to determine whether this was achieved without any loss of quality.

Endoscopic procedures are an important part of the diagnostic and therapeutic armamentarium of gastroenterologists. In some units endoscopic or medical quality improvement programs have been established. The Canadian Association of Gastroenterology has taken an active role in the review of quality standards in endoscopy (1). This survey was intentionally undertaken in teaching hospitals, and it is recognized that as such there was an inherent potential bias. It is likely that the appropriateness of endoscopic procedures needs to be based on accepted standards of practice (2) and accepted indications, and needs to be constantly monitored by a peer-review process to ensure quality maintenance. Basing 'appropriateness' of rates of one procedure on rates of other endoscopic procedures or of in-patient beds is unlikely to be valid.

This survey only addressed the issue of the quantity of endoscopies performed, and not the quality and outcome of procedures. The Alberta Endoscopy Project has been established to attempt to address issues of endoscopy outcome. It is hoped that the information obtained as a result of this study may be used to identify means of modifying endoscopic practices across Canada. We believe that the present survey clearly establishes that there is a very wide range of endoscopic utilization in these eight teaching hospitals, with approximately comparable rates of procedures of out-patient 
versus in-patient procedures and of gastroscopies versus colonoscopies, but no obvious linking of the ratios of inpatients:out-patients versus total number of designated gastrointestinal beds or total number of hospital beds. We also noted with interest that many units are staffed with 'other staff rather than with RNs, and cost saving opportunities may be available to perform more endoscopies.

\section{CONCLUSIONS}

Endoscopic use varies widely in major teaching hospitals. We propose that the appropriateness of endoscopic procedures be based on adherence to standard guidelines with procedures in place at each institution to ensure guideline adherence. We suggest that appropriateness cannot be based on comparing one unit with another in terms of procedures performed per gastrointestinal bed, in-patient bed or endoscopist.

ACKNOWLEDGEMENTS: We express our sincere appreciation to Drs J Baker, Toronto; A Bardum, Montreal; L DaCosta, Kingston; J Ferguson, Edmonton; B Salena, Hamilton; S Stordy, Vancouver; CN Williams, Halifax.

\section{REFERENCES}

1. Bailey RJ, Barkun A, Brow J, et al. Consensus in endoscopy. Can J Gastroenterol 1996;10:237-42.

2. Morrissey JF, Reichelderfer M. Gastrointestinal endoscopy. N Engl J Med 1991;325:1142-9. 


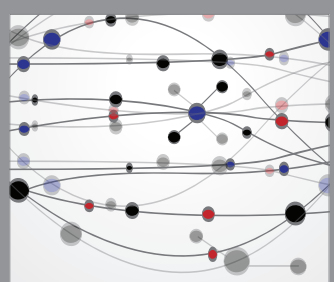

The Scientific World Journal
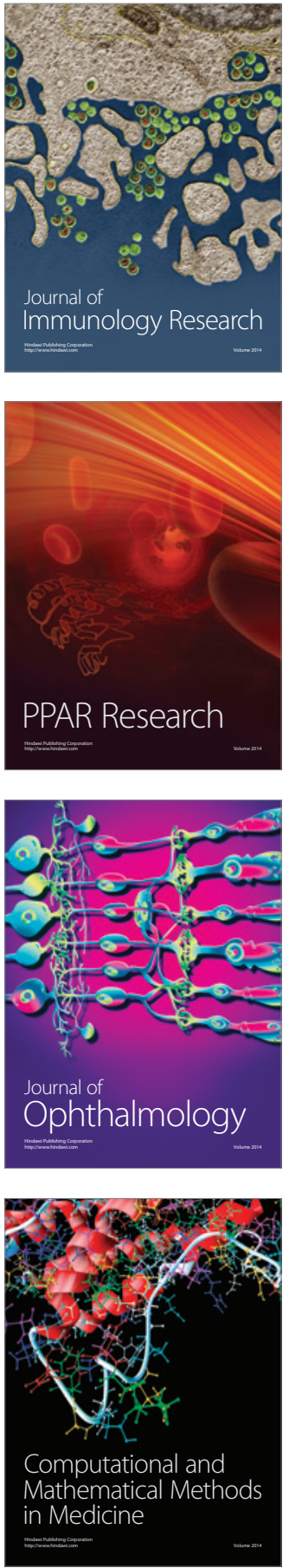

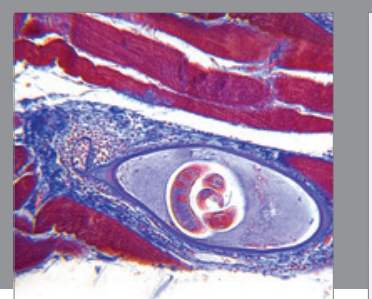

Gastroenterology Research and Practice

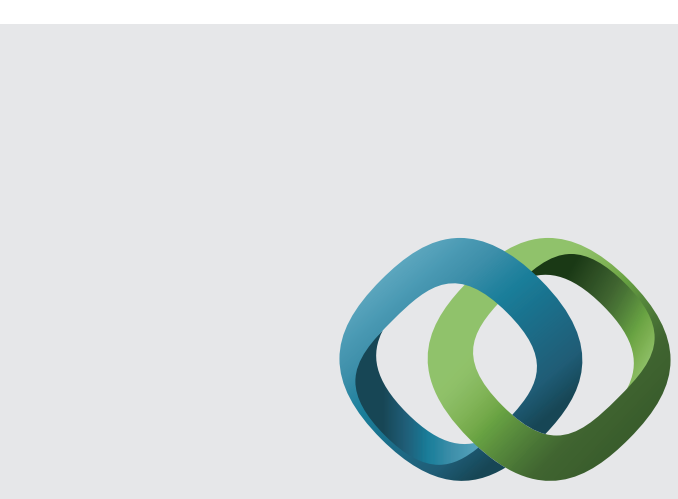

\section{Hindawi}

Submit your manuscripts at

http://www.hindawi.com
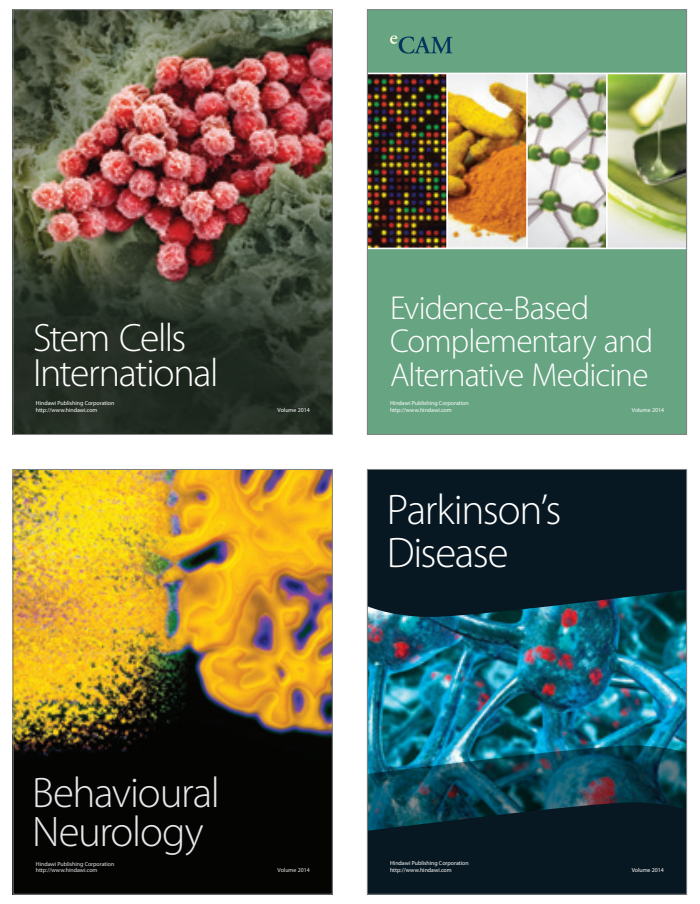
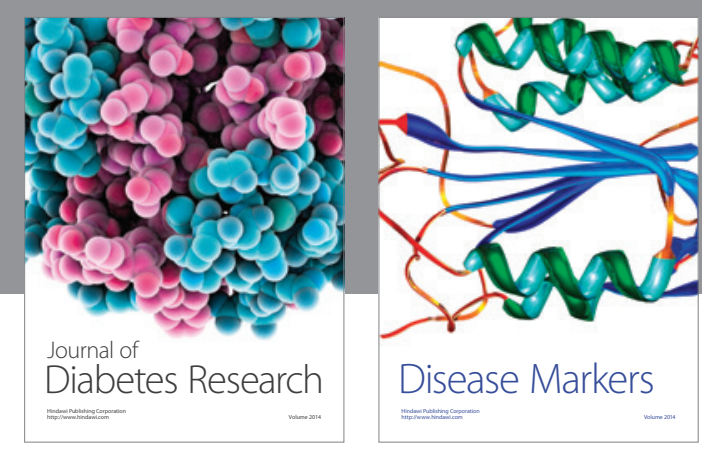

Disease Markers
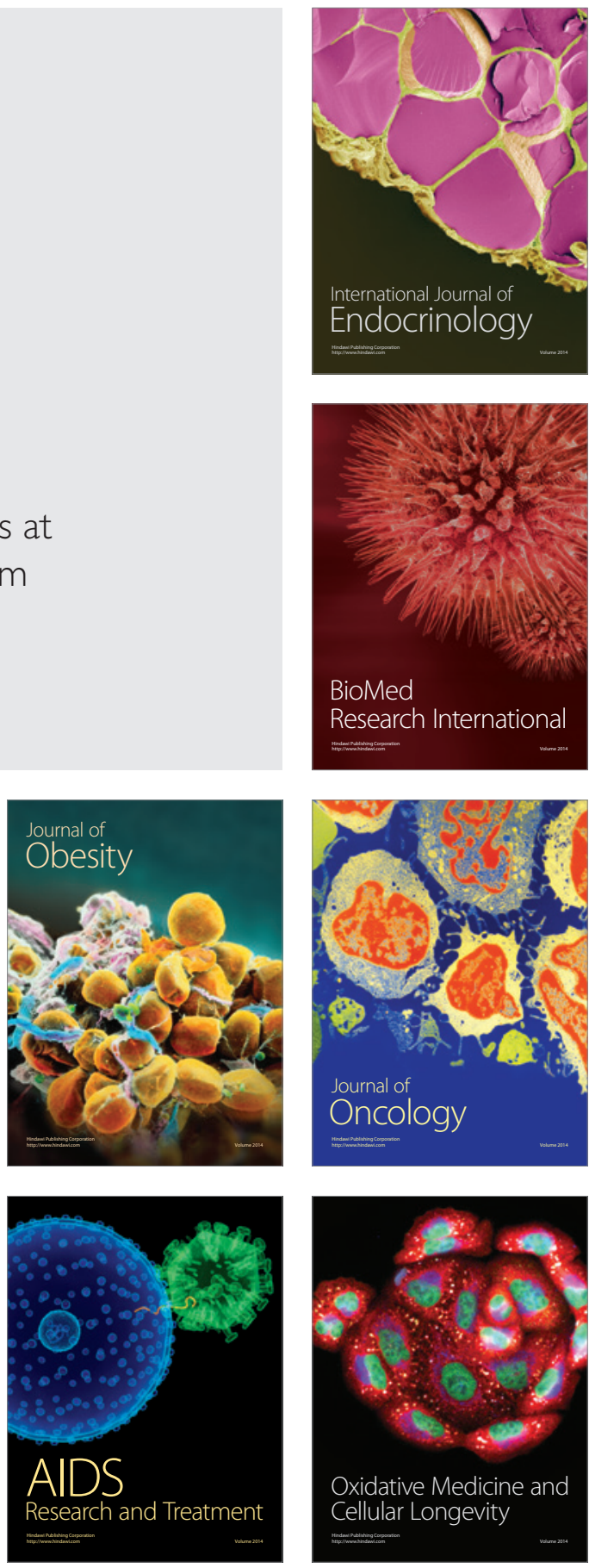